\title{
Student Learning Objectives: What Instructors Emphasize in Short-Term Study Abroad
}

\author{
Elizabeth Niehaus \\ University of Nebraska - Lincoln
}

Taylor C. Woodman

University of Maryland - College Park

\author{
Angela Bryan \\ Ashley Light \\ Erika Hill \\ University of Nebraska - Lincoln
}

\begin{abstract}
:
Given that higher education institutions are increasingly utilizing short-term study abroad courses as a means to develop students' intercultural competency, it is important to determine if and how the instructors leading these programs are incorporating intercultural learning into their courses. By examining learning objectives embedded within syllabi from short-term study abroad courses, the purpose of this study was to identify the relative extent to which instructors emphasize disciplinary and intercultural learning in teaching short-term study abroad courses, and to examine the types of intercultural learning that instructors are explicitly including in their courses. Findings point to a wide diversity of emphasis on disciplinary content and intercultural learning, with slightly more courses emphasizing disciplinary content than intercultural learning. Of those learning objectives that focus on intercultural learning, the vast majority focused on intercultural knowledge rather than skills or attitudes.
\end{abstract}

\section{Introduction}

As the world has become increasingly interconnected, the problems affecting the US have become more complex, interdisciplinary, and interdependent. As a result, governmental agencies and educational associations have stressed the importance of developing globally competent citizens "who understand how other peoples think, how other cultures work, and how other societies are likely to respond to American action" (American Council on Education [ACE], 1998, p. vii). The reality that "global integration is now our shared context" (American Association of Colleges \& Universities [AAC\&U], 2007, p. 21) has prompted organizations such as the ACE, the AAC\&U, and the Association of Public \& Land-Grant Universities (APLU, 2004) to encourage Americans to become more globally and interculturally competent in order to compete economically and address significant worldwide problems. 
In response to such calls to enhance the global competency of their citizenry, U.S. higher education institutions have increasingly focused on internationalization. According to a 2016 survey performed by the American Council on Education (ACE), 47\% of institutions included internationalization among the top five priorities in their strategic plans, and nearly half (49\%) of institutional mission statements included reference to international or global activities (Helms \& Brajkovic, 2017). Specific efforts to internationalize campuses included partnering with overseas institutions, recruiting and enrolling more international students, incorporating global perspectives into the curriculum, and increasing the number of U.S. students who study abroad. Among these, study abroad was identified as the top internationalization priority by surveyed institutions (Helms \& Brajkovic, 2017), indicating that it serves as a key strategy in institutions' broader internationalization efforts.

Study abroad as an institutional priority of internationalization has created significant growth in student mobility at U.S. universities. According to the Institute for International Education (IIE), the number of students studying abroad has tripled in the past two decades (IIE, 2018), with a growing majority of these students participating in short-term programs of eight weeks or less (IIE, 2017). As a shorter, more focused alternative to their semester- or year-long counterparts, short-term study abroad (STSA) programs provide an opportunity for students from nontraditional backgrounds or disciplines to participate in an international experience (Spencer \& Tuma, 2007). As a result, STSA has become the most common form of study abroad for U.S. college students (IIE, 2017), with a majority of these programs developed and directed by faculty members or other instructors at individual U.S. institutions (Tuma, 2007).

Study abroad is often assumed by many in higher education to include a strong emphasis on intercultural learning: the development of students' intercultural knowledge, skills, and attitudes required for global competency. While intercultural learning may be an institutional goal for encouraging study abroad participation, short-term programs typically allow faculty members/instructors leading study abroad programs a great deal of autonomy in determining the content and purpose of the course (Mapp, 2012). This provides an opportunity for instructors to articulate the disciplinary and intercultural learning objectives they consider to be essential to the learning experience. For this reason, it is important to examine the learning objectives identified by instructors of STSA abroad courses to determine how these objectives align with the institutional imperative to produce globally competent students.

\section{Short-Term Study Abroad}

Although there is evidence that STSA programs have the potential to advance students' global competency in areas such as intercultural knowledge and sensitivity (Anderson, Lawson, Rexeisen, \& Hubbard, 2006; Czerwionka, Artamonova, \& Barbosa, 2015), global and cultural awareness (Chieffo \& Griffiths, 2004; Kurt, Olitsky, \& Geis, 2013; Lumkes, Hallett, \& Vallade, 2012), cross-cultural skills (Kitsantas, 2004), and cultural adaptability (Mapp, 2012), other studies have produced less positive results (e.g., Gullekson, Tucker, Coombs, \& Wright, 2011; Kehl \& Morris, 2007; Medina-LopezPortillo, 2004). Such mixed findings have promoted skepticism of the academic and developmental benefits of STSA programs. For example, Woolf (2007) stressed that a fine line exists between education abroad and educational tourism, stating that educators must always question the content and purpose of short-term programs, as "[i]n many cases, content will be of marginal validity, and 
the purpose may well have more to do with finance and publicity than with learning and teaching" (p. 503). Additionally, a number of studies have pointed to the potential for longer-term study abroad programs to lead to greater intercultural learning (Dwyer, 2014; Paige \& Vande Berg, 2012), further questioning the efficacy of STSA programs in promoting global competence.

The diversity of outcomes identified in the research may be because study abroad, and in particular short-term study abroad, is an umbrella term for a variety of experiences, and different types of experiences may serve different purposes. As Tuma (2007) noted, short-term study abroad programs are created and implemented in a number of different ways. For example, some programs are offered through direct enrollment in a foreign institution, other U.S. institutions, or third-party agencies, often providing a highly structured program that may or may not align with the home institution's study abroad goals. Other options are hybrid programs, in which institutions partner with third-party providers to assist in program implementation and administration of the experience, while still allowing course instructors to tailor the program to their goals. Still other programs are created and led by course instructors from the home institution, either as stand-alone courses or as embedded travel within a regular term-long course. This option allows maximum flexibility in regard to content and overall curriculum integration.

Leaders of faculty-led short-term study abroad (FLSTSA) programs typically design their courses as discipline-based experiences that complement or expand an institution's existing curriculum. These courses focus on issues within the host country or region, providing a comparative approach to the issues and the ability to utilize materials or resources from other contexts (site visits, guest lectures, etc.) to enhance disciplinary learning (Hovde, 2002). As the content and purpose of these courses are often determined by individual faculty leaders, instructors may pay less attention to intercultural learning in favor of disciplinary content, often due to disciplinary socialization (Lutterman-Aguilar \& Gingerich, 2002). For this reason, many scholars and practitioners argue that instructors leading these more focused, topical courses must explicitly incorporate intercultural learning into the study abroad experience and intentionally engage students in cross-cultural learning opportunities in order to maximize the potential for global competence development (Amel \& Uhrskov, 2007; Anderson, Lorenz, \& White, 2016; Braskamp, Braskamp, \& Merrill, 2009; Gaia, 2015; Hovde, 2002; Twombly, Salisbury, Tumanut, \& Klute, 2012).

Although higher education scholars promote intercultural learning as an important component of the study abroad experience, do faculty members leading STSA programs share this view? Research indicates that faculty members' goals for study abroad are influenced by their individual backgrounds and disciplinary cultures. In a survey of more than 400 instructors who had taught short-term study abroad courses, Niehaus and Wegener (2017) identified five different types of goals for short-term study abroad: course content, cultural learning, career development, travel skills, and challenging ethnocentrism. Among these, cultural learning was the most strongly endorsed goal, although this varied by discipline, with those in area studies/foreign languages and journalism/communications endorsing this goal the most and those in STEM disciplines endorsing it the least. 


\section{Intercultural Learning}

While enhancing students' global competence is frequently cited as a goal of study abroad (Hovde, 2002; Lewin, 2009; Lincoln Commission, 2005; Musil, 2006; Twombly, Salisbury, Tumanut, \& Klute, 2012), there is little consensus on the meaning of this concept. This ambiguity is further complicated by the wide variety of terms in the literature used to describe global competence, including intercultural competence, intercultural effectiveness, cultural intelligence, global mindedness, and global understanding. Despite the differences in terminology, each of these concepts encompasses specific knowledge, skills, and attitudes that are reflective of intercultural learning, defined by Bennett (2009) as the process of "acquiring increased awareness of subjective cultural context (world view), including one's own, and developing greater ability to interact sensitively and competently across cultural contexts" (p. S2). For this reason, in this article we use the term intercultural learning to encompass globally and culturally related learning.

Intercultural knowledge, skills, and attitudes are a basis for many of the descriptions of intercultural learning and related terms found in the literature. For example, Hunter, White, and Godbey (2006) defined global competency as "having an open mind while actively seeking to understand cultural norms and expectations of others, leveraging this gained knowledge to interact, communicate, and work effectively outside one's environment" (p. 277). Deep cultural knowledge, intercultural communication skills, and an open attitude toward difference are essential components of this definition. Additionally, the Organisation for Economic Cooperation and Development (OECD, 2016) stated that global competency requires knowledge of global issues and world systems, as well as intercultural knowledge and understanding; skills such as the ability to communicate effectively with people from other cultures or countries and to see the world from others' perspectives (empathy); and attitudes such as openness toward people from other cultures or countries and respect for others' culture.

A number of scholars and associations have identified the importance of knowledge, skills, and attitudes that demonstrate intercultural learning. According to Bennett (2009), the knowledge required for intercultural competency begins with an awareness of one's own culture, which is necessary for individuals to recognize cultural differences. Individuals must also understand world history, issues, conditions, and events that have shaped cultures and societies (AAC\&U, 2007; Olson, Green, \& Hill, 2005). Building on this knowledge, interculturally competent individuals possess skills to analyze, interpret, and relate, as well as to listen and observe (Deardorff, 2006). These skills also include critical and comparative thinking (AAC\&U, 2007; OECD, 2016; Olson et al., 2005), integrative thinking (AAC\&U, 2007; Olson et al., 2005), and foreign language competency (Lambert, 1993; OECD, 2016; Olson et al., 2005). The final component, attitudes, is considered the foundation to the development of intercultural competence (Deardorff, 2006). According to Deardorff (2006), openness-being receptive to new ideas and experiences - and curiosity are requisite attitudes for the knowledge acquisition and skill development associated with intercultural competence. Additional attitudes identified in the literature included tolerance for ambiguity (Lilley et al., 2017; Olson et al., 2005), sensitivity and respect for differences (Lilley et al., 2017; Olson et al., 2005; OECD, 2016), and personal and social responsibility (AAC\&U, 2007; Lilley et al., 2017; OECD, 2016). 


\section{Purpose}

Given that higher education institutions are increasingly utilizing FLSTSA as a means to develop intercultural competency in students (Braskamp et al., 2009; Twombly et al., 2012), it is important to determine if and how the instructors leading these programs are incorporating intercultural learning into the objectives of their courses. As previously noted, the leaders of FLSTSA programs have a great deal of control over the content of these courses, and some instructors may choose to emphasize disciplinary learning over intercultural learning due to their individual backgrounds or disciplinary cultures (Lutterman-Aguilar \& Gingerich, 2002). The purpose of this study was to identify the relative extent to which instructors emphasize disciplinary and intercultural learning in teaching short-term study abroad courses, as articulated through the student learning objectives outlined in course syllabi, and to examine the types of intercultural learning objectives that instructors are explicitly including in their courses. We also sought to identify and describe any additional learning objectives that instructors were including in their courses that could not be classified as disciplinary or intercultural learning.

\section{Methods}

In order to explore the articulated learning objectives for FLSTSA courses, we examined the syllabi for these courses. As Grauerholz and Gibson (2006) argued, syllabi can be an important source of information about the goals that instructors have in their courses, how they communicate those goals to students, and how those goals align (or not) with broader disciplinary or institutional goals.

\section{Data Collection}

For this study, we created an online instrument to survey and catalog syllabi from instructors leading short-term study abroad courses, which are defined as programs lasting less than eight weeks (IIE, 2015). To recruit participants to complete the survey, during the fall of 2015 we sent a link directly to coordinators for short-term programming or directors of U.S. university study abroad offices working at the top short-term programs by institution type as indicated by the Institute of International Education's 2014 Open Doors report. Study abroad office staff members were asked to forward the link directly to instructors who had taught short-term courses within the past year. Four hundred and seventy-three course instructors across 72 institutions responded to the survey. Of the 473 responses, half of the respondents were randomly selected to upload a syllabus, and 113 instructors chose to do so.

\section{Data Analysis}

Our data analysis focused on quantitative and qualitative content analysis (Krippendorf, 2013). Quantitative content analysis was used to identify the relative emphasis on disciplinary and intercultural learning reflected in short-term study abroad syllabi, and qualitative content analysis was employed to examine the types of intercultural learning that instructors were including in syllabi.

Quantitative content analysis.

Following Krippendorff's (2013) description of the stages of content analysis, our analysis began with identifying the unit of analysis (unitizing) and sampling those units, followed by coding and then reducing the data into a usable format. 
Unitizing and sampling.

To begin our analysis, we focused our attention on the stated student learning objectives (SLOs) of the syllabi to determine instructors' emphasis on disciplinary and intercultural learning within the short-term programs they facilitate. Due to variation in how syllabi are constructed, we identified SLOs from any section in the syllabi that was labeled as or described intended student learning outcomes, course/learning objectives, or course goals. Syllabi files shared by course instructors that did not contain SLOs were removed from analysis leaving us with 84 syllabi to review. Using complete sentences or bulleted points as our unit of analysis, we identified 663 SLOs across all 84 syllabi with each syllabus containing between 2 and 23 SLOs.

Coding.

Following the identification of SLOs across all syllabi, four different codes were created to classify each of the SLOs. The four codes that could be assigned to each SLO were disciplinary, intercultural, both, and neither.

Disciplinary. To determine the discipline, we assigned each course syllabi a discipline coding designation using the National Center for Educational Statistics' Classification of Instructional Programs (CIP) code (NCES, n.d.). Designations were given based on the department sponsoring the course and/or the home discipline of the instructors teaching the course. After determining the discipline of the course, we reviewed SLOs against the CIP code descriptions to determine if the SLO aligned with learning the content, skills, or dispositions of the discipline or professional field within which the course was situated.

Intercultural. The intercultural coding definition indicated SLO content that focused on intercultural learning. SLOs within this category included learning a local language, learning about host country, and general learning about culture. Excluded from this category were any unstructured or optional activities or lectures from non-local instructors unless specifically about the host country.

Both. The both coding designation indicates when any SLO had elements of both intercultural and disciplinary content.

Neither. The neither coding designation captures any SLO that did not fall into the three previously mentioned designations.

To apply this coding scheme, we first refined our coding instructions by reviewing syllabi not associated with this research project. Following our testing phase, four members of the team independently coded each syllabus. Upon completion of independent coding, we calculated our interrater reliability to ensure an adequate level of consistency in our coding. Intercoder agreement was $82 \%$, averaged across all syllabi and all members of the coding team. After independently coding and determining our intercoder agreement, we discussed each SLO where we did not have $100 \%$ agreement to come to a consensus on the appropriate code for each.

Reducing the data.

In order to (a) standardize metrics across syllabi with vastly different numbers of coded units (SLOs) and (b) capture the relative emphasis of intercultural and disciplinary SLOs in each syllabus, we counted the number of disciplinary, intercultural, both, and neither coded SLOs across all syllabi. 
Determining these counts allowed us to calculate the relative emphasis on intercultural learning. We did this by taking the percentage of the SLOs that were coded as intercultural or both minus the percentage of the SLOs that were coded as disciplinary or both. This intercultural emphasis variable ranged from $100 \%$ to $-100 \%$, and indicated the extent to which the syllabus emphasized intercultural learning over disciplinary learning (positive values) or disciplinary learning over intercultural learning (negative values).

Qualitative content analysis.

Following our quantitative content analysis, we turned our attention to the intercultural and both designated SLO content in an effort to gain a deeper understanding of the type of learning indicated within the SLOs on short-term programs. Additionally, we further analyzed the neither coded SLOs to determine what type of learning falls outside of disciplinary content and intercultural learning on short-term programs.

Intercultural and both.

SLOs designated by us as intercultural and both were initially coded using an in vivo approach, to allow for themes to emerge naturally from the data (Saldaña, 2013). Upon completing the first round of coding, it was apparent that SLOs designated as intercultural and both could be further categorized into Knowledge (K), Skills (S), and Attitudes (A) (KSAs; Olson et al., 2005). In addition to the KSAs, a fourth category of Experience/Exposure (E/E) was added to capture objectives that described exposure to a culture, people, or concept, or gaining general experience (e.g., international travel), but did not necessarily imply that learning was taking place. A second round of pattern coding (Saldaña, 2013) was conducted to assign these KSAE/E codes to the SLOs.

After isolating the Knowledge, Skills, Attitudes and Experience/Exposure reflected in the SLOs, these codes were further analyzed to determine themes present within each of the categories. At both the first and second level of coding, the first author ensured thoroughness and accuracy by conducting a secondary review of the codes.

Neither.

To analyze codes originally designated neither, a primary coder was assigned to use an in vivo approach for first round coding (Saldaña, 2013). The codes that emerged during this round were collapsed into central themes with sub-themes using axial coding. After completion of the coding of the neither designations, a discussion and second level review was conducted by the first author to ensure thoroughness and accuracy.

\section{Results}

Based on their CIP code designations, the 84 syllabi in this study covered a broad range of disciplines: 11 syllabi were from Visual and Performing Arts; 9 each from Education and Social Sciences; 8 from Business; 7 each from Heath Studies/Professions and Agriculture and Natural Resources; 6 each from General Humanities and Interdisciplinary Studies; 5 each from Science, Technology, Engineering, and Mathematics (STEM) fields and Foreign Languages; 3 each from Area/Ethnic Studies, Communication, Architecture, and Public Administration; and 1 from Homeland Security (numbers add up to more than 84 total as a few syllabi represented multiple disciplinary areas). The majority of syllabi $(n=46)$ were for courses in Europe, with 18 for courses in Latin America and the Caribbean, 9 for courses in Asia, 6 for courses in Oceania, 3 for courses in 
Africa, and 1 each for courses in North America or the Middle East/North Africa. The syllabi represented courses at 53 different colleges and universities across the United States.

\section{Categorization of Student Learning Objectives}

The initial coding resulted in the following distributions: $32.28 \%$ of SLOs $(n=214)$ were coded as disciplinary content (D), 16.44\% $(n=109)$ were coded as intercultural learning $(I), 39.52 \%(n=262)$ were coded as both disciplinary and intercultural $(\mathrm{B})$, and $11.76 \%(\mathrm{n}=78)$ were coded as neither disciplinary nor intercultural $(N)$. Since B encompasses both I and D, 55.96\% $(n=371)$ of the learning objectives reflected some level of intercultural learning (alone or in combination with disciplinary content), and $71.79 \%(\mathrm{n}=476)$ reflected some amount of disciplinary content (alone or in combination with intercultural learning).

Figure 1. Intercultural and disciplinary emphasis in FLSTSA syllabi.

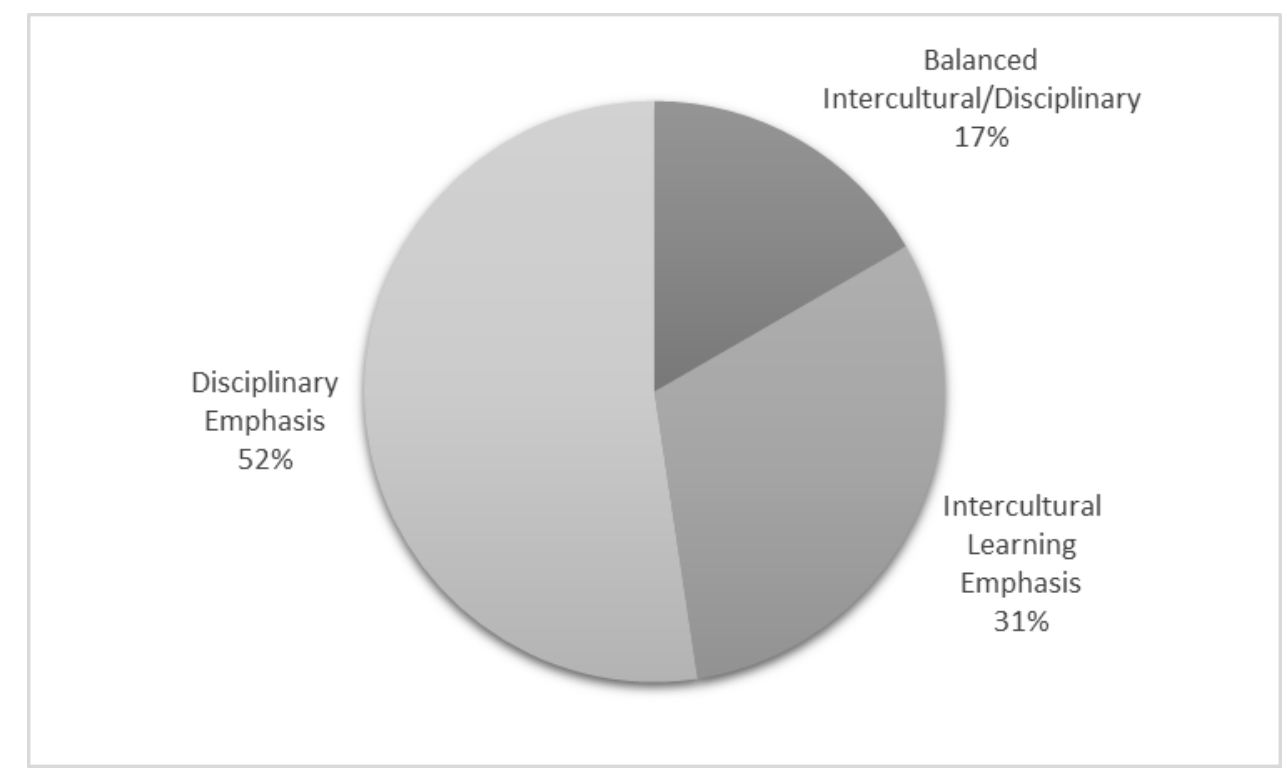

Figure 1 shows the distribution of syllabi that were categorized as having more emphasis on intercultural learning, more emphasis on disciplinary content, or an equal distribution of both types of SLOs. Of the 84 syllabi analyzed, 14 syllabi (17\%) were evenly focused on both disciplinary content and intercultural learning; their "intercultural emphasis" score (the difference between the percentage of SLOs in the syllabi that focused on intercultural learning and those that focused on disciplinary content) was zero. Eleven $(13 \%)$ of these only contained SLOs coded as both or neither, while three (4\%) had both and/or neither coded SLOs along with an equal number of SLOs focused on disciplinary content and intercultural learning. Twenty-six syllabi (31\%) had a positive intercultural emphasis score, indicating that they contained more SLOs focused on intercultural learning than disciplinary content. Forty-four syllabi $(52 \%)$ had a negative intercultural emphasis score, indicating that they contained more SLOs focused on disciplinary content than intercultural learning. Of those that had more emphasis on disciplinary content, $5(6 \%)$ syllabi only contained SLOs that focused on disciplinary content, with no SLOs that included intercultural or any other non-disciplinary learning. 
Although it is clear from Figure 1 that there were more syllabi that emphasized disciplinary content over intercultural learning than vice versa, the extent to which different syllabi emphasized one area of learning over the other varied widely. Figure 2 illustrates the distribution of intercultural emphasis scores across syllabi.

Figure 2. Relative emphasis on intercultural learning in FLSTSA syllabi.

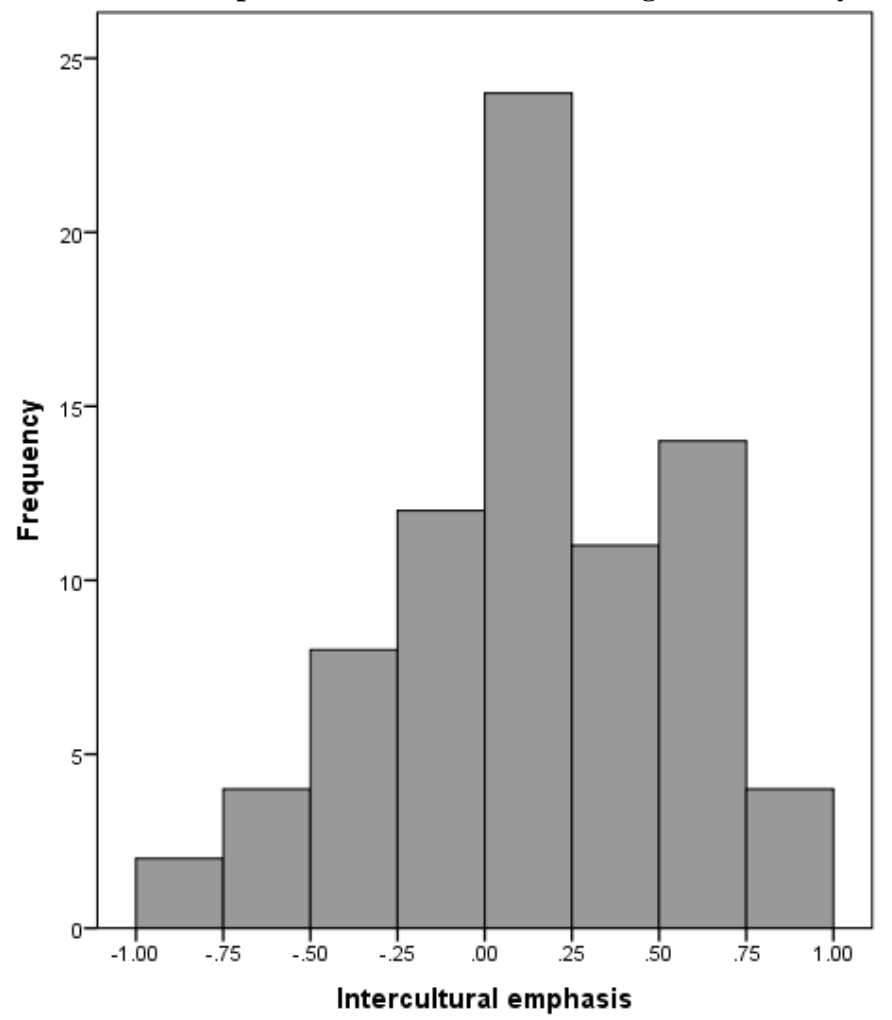

Note: Negative values indicate more disciplinary content-focused SLOs while positive values indicate more intercultural learning focused-SLOs in each syllabus.

\section{Decoding Intercultural Learning}

After the initial coding of SLOs as intercultural, disciplinary, both, or neither, we isolated all SLOs coded as intercultural and both in order to further analyze what types of intercultural learning objectives were included in syllabi. We first coded in vivo, and then applied codes for intercultural knowledge, skills, and attitudes, along with more general experience/exposure. Because SLOs were coded in sentence units, several SLOs related to more than one KSAE category. In total, the 371 SLOs from the syllabi that included some form of intercultural learning yielded $508 \mathrm{KSAE}$ classifications across 77 syllabi that contained SLOs originally coded as either intercultural or both.

Knowledge.

The knowledge category was the largest, with $75 \%(n=279)$ of interculturally-focused SLOs focusing on some aspect of intercultural knowledge; $99 \%$ of syllabi $(n=76)$ contained at least one SLO focusing on intercultural knowledge. The SLOs in this category focused on learning about the history, society, culture, language, physical environment, and institutions (government/politics, economics, religion, education, medicine, business/industry, etc.) of the host countries/regions, as well as knowledge of issues and current events impacting these countries and the world. Cultural 
learning was comprised of knowledge specific to the host countries/regions, as well as more general knowledge about topics such as cultural competency, cultural humility, diversity, ethnocentrism, and intercultural communication. Aspects of material culture (art, architecture, music, etc.) were also included as part of cultural learning. Examples of SLOs that reflected building students' intercultural knowledge included:

- "Research and examine the social, political, environmental, cultural, and spiritual systems in place in Kuala Lumpur and Penang, Malaysia." (Educational Psychology course in Malaysia)

- "Knowledge of Cuban geography, issues and events." (Business administration course in Cuba)

- "Articulate their understanding of the key aspects of Japanese culture emphasized in the course, including its geography, language, values, customs, religion and history." (Art course in Japan)

- "Define and recognize ethnocentrism and ethnocentric assumptions." (French Language course in France)

- "Extend their understanding of Africa through the study of literature." (Teacher Education course in Tanzania)

Skills.

The skills category was the second largest, with $40 \%(n=147)$ of interculturally-focused SLOs including some aspect of skills development; $36 \%$ of syllabi $(n=28)$ contained at least one SLO focusing on intercultural skills. These skills included communication skills, such as foreign language and intercultural communication skills; critical and comparative thinking skills, such as knowledge integration and reflection; technical (research) skills to help students learn about the world; and coping/resiliency skills, such as flexibility in difficult or unfamiliar environments. Examples of intercultural skills articulated in syllabi included:

- "Effectively use and understand some basic phrases in the German, Czech, and Polish language." (Engineering course in Austria, Poland, and the Czech Republic)

- "Communication skills including interactions with persons from another culture." (Business Administration course in France)

- "Coping with unfamiliar and challenging settings with resiliency." (Communications course in France)

- "Students will be able to integrate knowledge and skills in applications that facilitate student articulation and response to social, ethical, environmental and economic challenges at local, national and international levels." (Hospitality Management course in China)

Attitudes.

The attitudes category was the third largest, with only $14 \%(n=50)$ of interculturally-focused SLOs including the development of attitudes related to intercultural competence; $17 \%$ of syllabi 
$(n=13)$ contained at least one SLO focusing on intercultural attitudes. The attitudes that were included in SLOs primarily emphasized sensitivity/respect for differences; self-awareness of and appreciation for one's own culture; awareness of one's own identity, biases, and self in the world; openness to or appreciation for new ideas; and empathy (taking multiple perspectives). SLOs that reflected changes in students' attitudes included:

- "Another important goal is to instill within the students an appreciation for other cultures that creates a life-long desire to travel and broaden life experiences." (Interior Design course in England)

- "Developing greater acknowledgement and appreciation for one's own culture and cultural heritage." (Family Studies course in Brazil)

- "Appreciation for multiple perspectives in New Zealand." (Communications course in New Zealand)

Exposure and experience.

The final category of exposure and experience was the least common, with $9 \%(n=32)$ of interculturally-focused SLOs describing exposure to a culture, people, concept, or experience, but not necessarily implying that learning was taking place; $22 \%$ of syllabi $(n=17)$ contained at least one SLO focusing on intercultural exposure/experience. Examples of objectives within this category included touring Salzburg, Austria; participating in cultural activities; interacting with international clients; experiencing international travel; and participating in the archaeological process to reconstruct the lives of ancient Greeks. While these objectives did not explicitly indicate that students were expected to learn from these experiences, exposure to these types of experiences may promote learning by providing a foundation on which to build intercultural knowledge. Examples of exposure and experience focused-SLOs included:

- "An opportunity to experience another culture." (History course in the United Kingdom)

- "To experience first hand life in a Mediterranean country." (Archeology and Art History course in Greece)

- "Experience a foreign culture." (Agricultural Business course in Costa Rica)

Intercultural learning in syllabi.

Across the 77 syllabi that contained some form of intercultural learning SLOs, the most common type of syllabus contained only knowledge-related objectives ( $44 \%$ of syllabi, $\mathrm{N}=34)$. Other syllabi contained knowledge and experience/exposure SLOs (10\% of syllabi, $\mathrm{N}=8)$; knowledge, skills, and experience/exposure ( $8 \%, \mathrm{~N}=6)$; knowledge, skills, and attitudes ( $6 \%$ of syllabi, $\mathrm{N}=5$ ); and knowledge and attitudes (5\% of syllabi, $\mathrm{N}=4$ ). Two syllabi contained SLOs focusing on knowledge, attitudes, and exposure/experience; one syllabus contained only attitude-focused SLOs; and one syllabus contained SLOs covering all four areas (knowledge, skills, attitudes, and experience/exposure). See Table 1.

Table 1. Knowledge, skills, attitudes, and experience/exposure in FLSTSA syllabi. 


\begin{tabular}{|l|l|}
\hline Types of Intercultural Learning & \% of Syllabi (N) \\
\hline Knowledge Only & $44 \%(\mathrm{~N}=34)$ \\
\hline Knowledge and Experience/Exposure & $10 \%(\mathrm{~N}=8)$ \\
\hline Knowledge, Skills, and Experience/Exposure & $8 \%(\mathrm{~N}=6)$ \\
\hline Knowledge, Skills, and Attitudes & $6 \%(\mathrm{~N}=5)$ \\
\hline Knowledge and Attitudes & $5 \%(\mathrm{~N}=4)$ \\
\hline Knowledge, Attitudes, and Experience/Exposure & $3 \%(\mathrm{~N}=2)$ \\
\hline Knowledge, Skills, Attitudes, and Experience/Exposure & $1 \%(\mathrm{~N}=1)$ \\
\hline Attitudes Only & $1 \%(\mathrm{~N}=1)$ \\
\hline
\end{tabular}

\section{Unpacking Neither}

Through the course of our initial coding of SLOs in our data, we discovered a number of SLOs that we could not classify as intercultural nor disciplinary in nature; to account for this, we developed a neither category, and then coded these SLOs to determine what else instructors were attempting to teach in these study abroad courses.

Following the coding process, three main themes emerged from the neither-coded data. The first theme highlighted tangential skills that typically complemented the disciplinary learning objectives and provided broad guidance on the facilitation of learning within the study abroad course. Common SLOs in this theme discussed "effective presentation skills" or the "comparative skills" needed to be successful in this course or other international destinations. This theme addresses the integration of the study abroad course into the larger course structure as well as providing methods for transferring the learning in this course into larger academic and professional contexts or other communities or settings after the study abroad experience.

The second theme addressed the cohort- or team-based environment of a short-term study abroad program that focused on building a collaborative environment that embedded a diversity of thought into the learning space. These SLOs provided formalized guidance on ways to form teams and to process the multiple perspectives amongst the teams. This theme highlights the intimate and unique learning environment within which study abroad courses operate. These courses not only facilitate learning in new cultural contexts, they do so in small student cohorts that are living, learning, and traveling together for a number of days. SLOs within this theme aim to address this learning environment and prepare the students to build community and work across difference, but are not necessarily focused on cross-cultural differences.

The final theme emerging from the data provided objectives that focused on the student's internal growth and the processes that facilitate this type of growth. In this area, SLOs focused on personal perspectives and opinions as well as reflective tools needed to examine these perspectives. An example of an SLO in this theme included, "To relate course material to prior knowledge and personal experience." Like the second theme within the neither designation, these SLOs complement 
the intercultural learning objectives. The incorporation of these SLOs addresses the power of these types of courses to influence a student's perspective beyond the confines of the international experience and community.

\section{Limitations}

Syllabi are a primary way that instructors communicate course goals and content to students, which makes them a valuable tool to analyze the learning objectives in short-term study abroad courses. However, the broad diversity in the structure and content of these documents also presents a number of limitations for this study. There were a handful of syllabi for which we were not able to identify learning objectives, and thus we were not able to include these documents in our analysis. Additionally, due to the wide variety of material included in the syllabi, we were unable to analyze other syllabus content that might have been informative, such as detailed itineraries for the time abroad or assignment descriptions. As syllabi only contain information about what instructors intend to do in their courses, further research is also needed to determine how intended learning objectives translate (or not) to actual student learning.

In addition to the limitations of the syllabi documents themselves, we also acknowledge that, as in any content analysis, our findings are depending on the coding guidelines that we developed based on the literature on intercultural learning and the U.S. federal government's disciplinary definitions articulated in CIP code descriptions. The ways in which we conceptualized intercultural learning and disciplinary content may or may not align with how instructors themselves view the content of their courses.

\section{Discussion and Implications}

Considering the popularity of faculty-led, short-term study abroad courses (IIE, 2017; Tuma, 2007) and the divergent research findings regarding the potential for short-term study abroad to contribute to students' intercultural learning (e.g., Anderson et al., 2006; Chieffo \& Griffiths, 2004; Gullekson et al., 2011; Medina-Lopez-Portillo, 2004), there is a critical need to understand what types of learning outcomes these courses are designed to achieve. The results of this study point to different ways instructors incorporate disciplinary content and intercultural learning into their FLSTSA courses, and the types of intercultural learning that are and are not typically emphasized in these courses.

\section{Disciplinary Content and Intercultural Learning}

Across the 84 syllabi that we analyzed, we found that there was slightly more emphasis on disciplinary content than intercultural learning, although syllabi ranged from entirely disciplinaryfocused to almost entirely focused on intercultural learning Almost three quarters of SLOs had a disciplinary foundation, while just over half included some form of intercultural learning. Over half of the syllabi analyzed emphasized disciplinary content over intercultural learning, with five syllabi focusing only on disciplinary content; in contrast, there were no syllabi that focused only on intercultural learning, and only thirty percent emphasized intercultural learning over disciplinary content.

On the one hand, the fact that disciplinary learning would be strongly represented in these courses is not surprising as they are generally based in academic disciplines, where students earn 
credit within particular departments and programs. Faculty members are also generally socialized in disciplines (Lutterman-Aguilar \& Gingerich, 2002), with little formal training in intercultural learning (Goode, 2008). These results run somewhat contrary to Niehaus and Wegener's (2017) finding that instructors endorsed cultural learning goals more strongly than those related to course/disciplinary content. This discrepancy points to a possible disconnect between what instructors are thinking about in terms of the goals for their study abroad courses and what they actually articulate about student learning in their syllabi.

Although we generally positioned disciplinary content and intercultural learning as two separate areas of student learning, we found that there was actually a great deal of overlap between intercultural and disciplinary learning objectives: almost $40 \%$ of all SLOs in these syllabi were coded as both intercultural and disciplinary in nature, and the vast majority of syllabi included some array of both intercultural- and disciplinary-focused SLOs. This balance of intercultural and disciplinary learning, and the large number of SLOs that incorporated both into the same SLO, points to the ways in which instructors are integrating the disciplinary content of the course with the intercultural learning potential of the study abroad experience.

\section{Types of Intercultural Learning: Heavy Emphasis on Knowledge}

When it came to unpacking what was included in the intercultural SLOs, we found that there was a heavy emphasis on intercultural knowledge: all but one syllabus that included interculturallyfocused SLOs had at least one SLO that focused on gaining intercultural knowledge, and $75 \%$ of all interculturally-focused SLOs contained intercultural knowledge acquisition. In contrast, only 36\% of syllabi included any skill development, and only 14\% focused on developing attitudes related to intercultural competence. The skills and attitudes that were included aligned closely with those described in the intercultural competence literature (e.g., Olson et al., 2005), but the majority of syllabi did not include any intentional intercultural skill or attitude development.

This lack of attention to skills and attitudes raises concerning questions about the ability of many FLSTSA courses to facilitate students' intercultural competence development. Although intercultural knowledge is of course a key part of intercultural competence, as Deardorff (2006) asserted, attitudes of openness and curiosity are prerequisites for gaining appropriate intercultural knowledge, and there is a broad consensus that intercultural learning must go beyond basic knowledge acquisition for students to be truly interculturally competent (e.g., AAC\&U, 2007; OECD, 2016; and many others). As faculty members generally receive little formal training in intercultural competence (Goode, 2008), it is unsurprising that they might default to the most obvious types of intercultural SLOs and focus only on students' knowledge acquisition. If these courses are truly to be central to institutions' strategies to increase students' intercultural competence, however, it is likely that more support will be needed to help instructors intentionally integrate a more comprehensive approach to intercultural learning in their courses.

In addition to a heavy emphasis on intercultural knowledge acquisition, it was also noteworthy that there were a large number of SLOs that were intercultural in nature, but were not explicitly focused on knowledge, skills, or attitudes ( $9 \%$ of all interculturally-focused SLOs across $22 \%$ of syllabi); instead, they simply focused on exposing students to different countries or cultures, or providing opportunities for students to gain international experience. This focus on exposure and 
experience rather than what students should learn from that experience may indicate that these were imprecisely worded SLOs, but it may also be that faculty members writing these goals recognize the potential value of these experiences but are not able to articulate what students should learn from these experiences. This finding may reflect faculty members' lack of specific training in intercultural learning (Goode, 2008), but may also reflect the implicit expectation that experience will automatically lead to intercultural learning and intercultural competence development. As Woolf (2007) and Paige and Vande Berg (2012) have argued, however, simply sending students abroad and exposing them to different cultures is not enough; intercultural competence development requires intentional attention to all aspects of intercultural learning.

\section{Implications for Practice}

This study points to a number of implications for education abroad professionals working with instructors of short-term study abroad courses. First, it is important for education abroad professionals to understand the training that faculty members and other instructors do and do not have related to intercultural learning, and how that affects student learning in study abroad courses. Although a great deal of diversity exists in the background experiences of individual instructors, our findings point to key trends in the types of learning that instructors are emphasizing in their courses. Instructors must have the freedom to determine the content and structure of their courses, but education abroad professionals might provide sample SLOs that focus on intercultural learning, especially intercultural attitudes and skills, and examples of course activities that might be incorporated to achieve those learning objectives. Education abroad professionals might also work with instructional designers to further support instructors of short-term study abroad courses through trainings and one-on-one consultations to help with course development.

Second, education abroad professionals and other internationalization leaders in higher education institutions should consider the results of this study in critically examining the role of FLSTSA courses in their internationalization efforts. As Niehaus and Wegener (2017) argued based on their findings related to faculty members' goals for teaching study abroad courses, FLSTSA courses should not be the only way that institutions are facilitating intercultural competence development. These courses are better considered as one part of a broader constellation of internationalization efforts. The results of this study point to FLSTSA's contribution to students' intercultural knowledge but limited contribution to other aspects of intercultural competence development.

Finally, instructors, education abroad professionals, and researchers can all draw from the findings of this study to think critically about how we are assessing and researching short-term study abroad courses. If the intended SLOs of these courses are primarily focused on intercultural knowledge, assessments and research studies that focus on whether or not students develop intercultural skills and attitudes may not be the best measures of whether or not these courses are successful.

\section{Conclusion}

Higher education institutions are increasingly focusing on study abroad programs, especially short-term programs, as a means of fulfilling internationalization goals. Thus, the assessment of these programs stands as an imperative step in ensuring that study abroad programs are addressing 
key internationalization education principles and developing globally competent citizens. The results of this study demonstrate the range of disciplinary and interculturally-focused curriculum in these courses, as well as the variety of skills, attitudes, and experiences that faculty hope to accomplish through their course objectives. With a better understanding of the focus areas of these faculty-led study abroad courses, study abroad directors and internationalization leaders in higher education are better able to assess and think strategically about how study abroad programs can and should meet broader internationalization goals.

\section{References}

Amel, E., \& Uhrskov, A. (2007). Designing the academic course: Principles and practicalities. In S. E. Spencer \& K. Tuma (Eds.), The guide to successful short-term programs abroad (2nd ed., pp. 4758). Washington, DC: NAFSA: Association of International Educators.

American Council on Education. (1998). Educating for global competence: America's passport to the future. Washington, DC: Author.

Anderson, P. H., Lawton, L., Rexeisen, R. J., \& Hubbard, A. C. (2006). Short-term study abroad and intercultural sensitivity: A pilot study. International Journal of Intercultural Relations, 30(4), 457469.

Anderson, C. L., Lorenz, K., \& White, M. (2016). Instructor influence on student intercultural gains and learning during instructor-led, short-term study abroad. Frontiers: The Interdisciplinary Journal of Study Abroad, XXVIII, 1-23.

Association of American Colleges and Universities. (2007). College learning for the new global century. Washington, DC: Author. Retrieved from https://www.aacu.org/sites/default/files/files/LEAP/GlobalCentury_final.pdf

Association of Public and Land-Grant Universities. (2004). A call to leadership: The presidential role in internationalizing the university. Washington, DC: Association of Public and Land-Grant Universities. Retrieved from http://www.aplu.org/library/a-call-to-leadership-the-presidential-role-ininternationalizing-the-university/file

Bennett, M. J. (2009). Defining, measuring, and facilitating intercultural learning: A conceptual introduction to the Intercultural Education double supplement. Intercultural Education, 20(sup1), S1-S13.

Braskamp, L. A., Braskamp, D. C., \& Merrill, K. C. (2009). Assessing progress in global learning and development of students with education abroad experiences. Frontiers: The Interdisciplinary Journal of Study Abroad, XVIII, 101-118.

Chieffo, L., \& Griffiths, L. (2004). Large scale assessment of student attitudes after a short-term study abroad program. Frontiers: The Interdisciplinary Journal of Study Abroad, X, 165-177.

Commission on the Abraham Lincoln Study Abroad Fellowship Program. (2005, November). Global competence \& national needs: One million Americans studying abroad. Washington, DC: Author. Retrieved from http://www.aifs.com/pdf/lincoln_final_report.pdf

Czerwionka, L., Artamonova, T., \& Barbosa, M. (2015). Intercultural knowledge development: Evidence from student interviews during short-term study abroad. International Journal of Intercultural Relations, 49, 80-99.

Deardorff, D. K. (2006). The identification and assessment of intercultural competence as a student outcome of internationalization at institutions of higher education in the United States. Journal of Studies in International Education, 10(3), 241-266.

Dwyer, M. M. (2004). More is better: The impact of study abroad program duration. Frontiers: The Interdisciplinary Journal of Study Abroad, X, 151-163.

Gaia, A. C. (2015). Short-term faculty-led study abroad programs enhance cultural exchange and selfawareness. The International Education Journal: Comparative Perspectives, 14(1), 23-31.

Goode, M. L. (2008). The role of faculty study abroad directors: A case study. Frontiers: The Interdisciplinary Journal of Study Abroad, XV, 149-172. 
Grauerholz, L. \& Gibson, G. (2006). Articulation of goals and means in sociology courses: What can we learn from syllabi? Teaching Sociology, 34, 5-22.

Gullekson, N. L., Tucker, M. L., Coombs, G., \& Wright, S. B. (2011). Examining intercultural growth for business students in short-term study abroad programs: Too good to be true? Journal of Teaching in International Business, 22(2), 91-106.

Helms, R. M., \& Brajkovic, L. (2017). Mapping internationalization on U.S. campuses. Washington, DC: American Council on Education. Retrieved from http://www.acenet.edu/news-room/Pages/MappingInternationalization-on-U-S-Campuses.aspx

Hovde, P. (2002). Opening doors: Alternative pedagogies for short-term programs abroad. In S.E. Spencer \& K. Tuma (Eds.), The guide to successful short-term programs abroad (pp. 1-7). Washington, DC: NAFSA: Association of International Educators.

Hunter, W., White, G., \& Godbey, G. (2006). What does it mean to be globally competent? Journal of Studies in International Education, 10, 267-285.

Institute of International Education. (2015). Open Doors report on international educational exchange. Retrieved from http://www.iie.org/opendoors

Institute for International Education. (2017). Detailed duration of U.S. study abroad, 2005/6-2015/16. Retrieved from https://www.iie.org/Research-and-Insights/Open-Doors/Data/US-StudyAbroad/Duration-of-Study-Abroad

Institute for International Education. (2018). Open Doors 2017 executive summary. Retrieved from https://www.iie.org/Why-IIE/Announcements/2017/11/2017-11-13-Open-Doors-2017-ExecutiveSummary

Kehl, K., \& Morris, J. (2007). Differences in global-mindedness between short-term and semester-long study abroad participants at selected private universities. Frontiers: The Interdisciplinary Journal of Study Abroad, XV, 67-79.

Kitsantas, A. (2004). Studying abroad: The role of college students' goals on the development of crosscultural skills and global understanding. College Student Journal, 38(3), 441-452.

Krippendorff, K. (2013). Content analysis: An introduction to its methodology ( $3^{\text {rd }}$ ed.). Los Angeles, CA: Sage.

Kurt, M. R., Olitsky, N. H., \& Geis, P. (2013). Assessing global awareness over short-term study abroad sequence: A factor analysis. Frontiers: The Interdisciplinary Journal of Study Abroad, XXIII, 22-41.

Lewin, R. (Ed.). (2009). The handbook of practice and research in study abroad: Higher education and the quest for global citizenship. New York, NY: Routledge.

Lilley, K., Barker, M., \& Harris, N. (2017). The global citizen conceptualized: Accommodating ambiguity. Journal of Studies in International Education, 21(1), 6-21.

Lumkes, J. H., Hallett, S., \& Vallade, L. (2012). Hearing versus experiencing: The impact of a short-term study abroad experience in China on students' perceptions regarding globalization and cultural awareness. International Journal of Intercultural Relations, 36(1), 151-159.

Lutterman-Aguilar, A., \& Gingerich, O. (2002). Experiential pedagogy for study abroad: Educating for global citizenship. Frontiers: The Interdisciplinary Journal of Study Abroad, VIII, 41-82.

Mapp, S. C. (2012). Effect of short-term study abroad programs on students' cultural adaptability. Journal of Social Work Education, 48(4), 727-737.

Medina-Lopez-Portillo, A. (2004). Intercultural learning assessment: The link between program duration and the development of intercultural sensitivity. Frontiers: The Interdisciplinary Journal of Study Abroad, X, 179-199.

Musil, C. M. (2006). Assessing global learning: Matching good intentions with good practice. Washington, DC: Association of American Colleges and Universities. Retrieved from https://www.aacu.org/sites/default/files/files/publications/Global_Learning2006.pdf

National Center for Education Statistics. (n.d.). IPEDS Classification of Instructional Programs (CIP). Retrieved from https://nces.ed.gov/ipeds/cipcode/ 
Niehaus, E. \& Wegener, A. (2017, November). What are we teaching abroad? Faculty goals in short-term study abroad courses. Paper presented at the annual meeting of the Association for the Study of Higher Education, Houston, TX.

Olson, C., Green, M., \& Hill, B. (2005). Building a strategic framework for comprehensive internationalization. Washington DC: American Council on Education. Retrieved from http://www.madeleinefgreen.org/wp-content/uploads/2013/12/Building-a-Strategic-Framework-forComprehensive-Internationalization.pdf

Organisation for Economic Co-operation and Development. (2016). Global competency for an inclusive world. Paris, France: Author. Retrieved from http://www.oecd.org/pisa/aboutpisa/Globalcompetency-for-an-inclusive-world.pdf

Paige, R. M., \& Vande Berg, M. (2012). Why students are and are not learning abroad. In M. Vande Berg, R. M. Paige, \& K. Lou (Eds.), Student learning abroad: What our students are learning, what they're not, and what we can do about it (pp. 29- 58). Sterling, VA: Stylus.

Saldaña, J. (2016). The coding manual for qualitative researchers ( ${ }^{\text {rd }}$ ed.). Los Angeles, CA: Sage.

Spencer, S. E., \& Tuma, K. (2007). Introduction. In S. E. Spencer \& K. Tuma (Eds.), The guide to successful short-term programs abroad (2nd ed., pp. ix-xi). Washington, DC: NAFSA: Association of International Educators.

Tuma, K. (2007). Program models. In S. E. Spencer \& K. Tuma (Eds.), The guide to successful short-term programs abroad (2nd ed., pp. 41-45). Washington, DC: NAFSA: Association of International Educators.

Twombly, S. B., Salisbury, M. H., Tumanut, S. D., \& Klute, P. (2012). Study abroad in a new global century: Renewing the promise, refining the purpose. ASHE Higher Education Report, 38(4).

Woolf, M. (2007). Impossible things before breakfast: Myths in education abroad. Journal of Studies in International Education, 11(3/4), 496-509. 